Научная статья

УДК $81=512.31$

DOI: 10.18101/2305-459X-2020-4-137-143

\title{
ЛЕКСИКА ВОСПРИЯТИЯ МЯГКИХ И ТВЕРДЫХ ПОВЕРХНОСТЕЙ В БУРЯТСКОМ ЯЗЫКЕ И НАЦИОНАЛЬНОЙ ЯЗЫКОВОЙ КАРТИНЕ МИРА (зөөлэн и хатуу)
}

\author{
(C) Цыренов Бабасан Доржиевич \\ доктор филологических наук, доцент, \\ ведущий научный сотрудник, \\ Институт монголоведения, буддологии и тибетологии СО РАН \\ Россия, 670047, г. Улан-Удэ, ул. Сахьяновой, д. 6 \\ tsyrenovbabasan@mail.ru
}

\begin{abstract}
Аннотация. В статье рассматривается лексика восприятия жестких и мягких поверхностей в бурятском языке и бурятской национальной языковой картине мира. Прилагательные зөөлэн и хатуу кроме основного, прямого значения выражают новые значения на основе метафорического переноса. Данные значения отражаются в структуре словарной статьи толковых словарей. Если отсутствует толковый словарь, то эти значения обычно отображаются в двуязычном словаре. Эти значения могут описывать характер человека, его вербальные и невербальные действия, чувства, эмоции. Позитивные характеристики связываются с прилагательным зөөлэн 'мягкий'. Это вполне объяснимо: мягкий характер, мягкое обращение так же комфортны, как и мягкое сиденье, мягкая ткань. Противоположно этому некомфортное поведение, резкие слова, характер, душа ассоциируются с твердыми поверхностями. Исключением является характеристика таких положительных черт, как воля, решимость, которые тоже определяются прилагательным хатуy 'твердый'.

Ключевые слова: лексика восприятия; мягкий; твердый; языковая картина мира; характеристика; душа; слово; воля; прилагательное; бурятский язык.
\end{abstract}

Благодарность. Работа выполнена в рамках государственного задания (XII.193.1.5. Ментальность монгольских народов в зеркале языка. Номер госрегистрации № AAAA-A17-117021310266-8).

\section{Для цитирования}

Цыренов Б. Д. Лексика восприятия мягких и твердых поверхностей в бурятском языке и национальной языковой картине мира (зөөлэн и хатуy) // Вестник Бурятского государственного университета. Язык. Литература. Культура. 2020. Вып. 4. C. 137-143.

Введение. Под бурятской национальной языковой картиной мира мы подразумеваем результат отражения объективного мира обыденным (языковым) сознанием [9, с. 112] бурятского этноса. В то же время представляется возможным говорить о единой национальной языковой картине мира монгольских народов на основе их генетического родства и определенной степени тождества лексики и грамматики. Об этом могут свидетельствовать данные, полученные в исследованиях по перцепции, например по температурным ощущениям в калмыцком языке [4] и бурятском языке [15]. Подобные соответствия отмечаются 
и по другим разрядам перцептивной лексики, в том числе по тактильной лексике.

В данной работе мы ставим цель исследовать прилагательные осязания зөөлэн 'мягкий' и хатуy 'твердый' как в прямом значении выражения тактильного осязания, так и в аксиологическом, переносном - метафорическом и метонимическом. Материалом для исследования послужили данные из Электронного корпуса бурятского языка (Бурятский корпус - БК), двухтомного Бурятско-русского словаря [6; 7], Краткого словаря синонимов бурятского языка. Материалы из БК были извлечены методом сплошной выборки в поисковой системе корпуса и подвергнуты дистрибутивному анализу с целью распределения материала по значениям, которые были зафиксированы в БРС. Таким образом, собраны примеры, представляющие собой целые предложения из прозаических произведений или строфы из стихотворных произведений, в которых употребляются искомые слова.

Результаты. Тактильная лексика рассматривалась в большом количестве работ отечественных и зарубежных исследователей. В силу ограниченности объема журнальной статьи мы не можем делать подробный обзор этих работ, а отметим лишь несколько статей, диссертационных исследований и монографий, на которые мы будем опираться здесь. В связи с нашим материалом наибольший для нас интерес представляет диссертация О. А. Елисеевой «Концептуализация тактильных ощущений, связанных с поверхностью объекта» [8], в которой автор на основе обзора предыдущих работ $[1 ; 2 ; 11 ; 5$ и др.] приходит к выводам, что «...анализу тактильных ощущений в лингвистике уделено значительно меньше внимания, чем вопросам вербализации ощущений, полученных через остальные каналы восприятия действительности», и что «на сегодняшний день в лингвистике практически отсутствуют исследования, посвященные вопросу концептуализации тактильного восприятия языковыми средствами...» [8, c. 33]. Второй вывод закономерно проистекает из первого: отсутствуют исследования, поскольку «анализу тактильных ощущений в лингвистике уделено значительно меньше внимания». Работа О. А. Елисеевой и ряд других заполняют лакуны, обозначенные в ней. Также представляют интерес работы Е. В. Рахилиной [13], В. В. Кузьмина [10]. К этому ряду можно отнести и статью С. Е. Бачаевой, посвященную прилагательным калмыцкого языка, выражающим тактильные ощущения [4]. Ценность данной статьи для нашего исследования определяется еще и тем, что бурятский и калмыцкий языки являются родственными и входят в монгольскую группу алтайской языковой семьи. Свои наблюдения и выводы мы будем соотносить с таковыми в работе С. Е. Бачаевой.

По утверждению А. В. Нагорной, «осязание появляется у человека гораздо раньше всех остальных типов ощущений, еще на этапе эмбрионального развития» [12, с. 42]. В пользу своего утверждения она также приводит мнение Э. Б. де Кондильяка о том, «что только с помощью тактильных ощущений мы можем производить точную оценку объектов окружающего мира, и только тактильные ощущения поставляют нам информацию, обладающую истинностью для всех» [Там же]. Действительно, осязание является той конечной меркой, которая определяет истинность увиденного или услышанного. 
Б. Д. Цыренов. Лексика восприятия мягких и твердых поверхностей в бурятском языке и национальной языковой картине мира (зөөлэн и хатуу)

В бурятском языке представлен широкий спектр осязательной лексики, отображающей особенности поверхности, физических характеристик (плотность, упругость, температура, вес и т. д.).

В Бурятско-русском словаре зөөлэн в прямом значении переводится как 'мягкий', а в переносном — 'нежный, ласковый; обходительный, вежливый' [6, с. 405]. В рукописи Толкового словаря бурятского языка в статье на зөөлэн выделено всего три значения: «1) хатуу, хүжүүн бэшэ, дарахада бэлэнээр дарагдадаг, бамбагархан (мягкий); 2) шэлж. энхэргэн, үнжэгэн, налархай, урин (нежный, ласковый, вежливый); 3) грам. хэлэнэйнгээ дунда хэсэгые хатуу тангалайда дүтэлүүлжэ хэлэдэг (хашалган абяан тухай) (палатализованный, смягченный - о согласных звуках)» (ТСБЯ); рукопись. Здесь видно, что второе значение избыточно широкое и охватывает несколько значений русского эквивалента: «2. Приятный при ощущении, не раздражающий. М. свет. М. голос. 3. Плавный, размеренный. Мягкие движения. Мягкая посадка (о летательном аппарате: при минимальной скорости). 4. Кроткий, лишенный грубости, резкости. М. характер. 5. Не очень строгий, снисходительный, не суровый. М приговор» [14]. О потенциальной возможности выделения подобных значений в пределах второго - переносного - значения (оставим в стороне 1-е и 3-е значение) бурятского прилагательного зөөлэн свидетельствуют данные из Бурятского корпуса.

Значения бурятского прилагательного зөөлэн, приведенные выше, реализуются в сочетании с определенными существительными. Представим это в виде таблицы (табл. 1).

Таблийа 1

Переносные значения зөөлэн в бурятском языке

\begin{tabular}{|c|c|}
\hline Значение & Существительные \\
\hline $\begin{array}{l}\text { Приятный при ошущении, не раздра- } \\
\text { жающий }\end{array}$ & $\begin{array}{l}\text { абяан 'звук', дуун, хоолой 'голос', } \\
\text { һалхин 'ветер', hэбшээн 'ветерок', } \\
\text { үгэ 'слово', хараса 'взгляд' }\end{array}$ \\
\hline Плавный, размеренный & ябадал 'ход, походка' \\
\hline $\begin{array}{l}\text { Кроткий, литенный грубости, рез- } \\
\text { кости }\end{array}$ & $\begin{array}{l}\text { зан 'характер', сэдьхэл 'душа', мэхэ } \\
\text { 'обман (лесть)' }\end{array}$ \\
\hline $\begin{array}{l}\text { Не очень строгий, снисходитель- } \\
\text { ный, не суровый }\end{array}$ & хуули 'закон', хандаса 'отношение' \\
\hline
\end{tabular}

В данном случае налицо метафорический перенос физического качества на умозрительные, ментальные и общественные явления. На основе сходства основного значения значений 'мягкий при прикосновении' и значения 'приятный при ощущении, не раздражающий' с данным прилагательным сочетаются слова абяан, дуун 'звук, голос', һалхин, һэбшээн 'ветерок', үгэ 'слово', хараса 'взгляд', равно как и других значений 'плавный, размеренный', 'кроткий, лишенный грубости, резкости', 'не очень строгий, снисходительный, не суровый’. 
Перенос прямого значения слова с целью указания признаков других предметов указывает на его вторичность и первичность именно физического восприятия, которое было перенесено на явления, обозначаемые приведенными выше существительными.

Приведем несколько примеров переносного, метафорического употребления прилагательного зөөлэн:

— Яһалал зохидхон, зөөлэн хоолойтой басаган янзатай, - гэжэ дуугарба (Д. Эрдынеев, Энэ наһан, 1968) ' - Кажется, у девушки довольно хороший, мягкий голос, — произнес он';

Зөөлэн үгөөр асуужа байжа аажамаар хэлэ (Э.-Х. Галшиев, Бэлигэй толи, 1880-1915) 'Расспрашивай мягко и разговаривай спокойно';

Абаһаар тэрэ хүбүҮнэй зөөлэн һайхан сэдьхэл мэдэрээ гY? (А. Ангархаев, Yep, 1977) 'Сразу же почувствовала мягкий характер того юноши?'

«Иимэл даа эсэгэмни. ШэрҮҮншье hаa, урин зөөлэн зантай!» (А. Ангархаев, Үер 1977) '«Таков мой отец. Хоть и строг, но характер у него мягкий';

... зондо зөөлэн хуули бии болгохо зорилгоор хааниие эсэргүҮсэн бодоо юм (Ч. Цыдендамбаев, Банзарай хүбүүн Доржо, 1953) ‘...он восстал против царя, чтобы даровать народу мягкий закон (власть)';

В номенклатуре значений прилагательного хатуy, кроме основного значения 'твердый, жесткий; крепкий, прочный', выделено много значений, которые раскрывают весь его семантический потенциал. В каждом из значений предполагается употребление эксклюзивных определяемых, выраженных чаще всего существительными (например, исключение составляет субстантивировавшееся прилагательное духата).

В приведенной ниже таблице (табл. 2) отражены переносные значения прилагательного хатуy в БРС-II за исключением первого, основного значения и значений, которые регламентируют его парное употребление (9-е и 10-е значения). Значения с парным употреблением в целом дублируют переносные и прямое значения.

Таблииа 2

Переносные значения хатуу в «Бурятско-русском словаре» (2008)

\begin{tabular}{|c|c|}
\hline Значение & Существительные \\
\hline $\begin{array}{l}\text { 2) твёрдый, непоколебимый, } \\
\text { неизменныци, установленный }\end{array}$ & $\begin{array}{l}\text { зориг 'смелость; стремление’, бодол } \\
\text { 'мысль', гар 'рука', гурим ‘порядок, } \\
\text { режим', даабари 'задание', хүн 'человек’, } \\
\text { эрэ ‘мужчина', сэн 'цена', сэдьхэл 'дума' }\end{array}$ \\
\hline $\begin{array}{l}\text { 3) крепкий, } \\
\text { сильнодействуюшиий; густой }\end{array}$ & 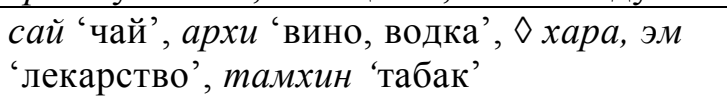 \\
\hline $\begin{array}{l}\text { 4) крепкий, здоровыц̆, } \\
\text { выноосливылй }\end{array}$ & xүн 'человек', морин 'конь, лошадь' \\
\hline 5) скупой & xүн 'человек' \\
\hline $\begin{array}{l}\text { 7) жестокий; суровый, } \\
\text { строгий }\end{array}$ & $\begin{array}{l}\text { зарлиг 'указ’, хүмүүжэлгэ 'воспитание', } \\
\text { сэдьхэл 'душа', саг 'время', хабар 'весна', }\end{array}$ \\
\hline
\end{tabular}


Б. Д. Цыренов. Лексика восприятия мягких и твердых поверхностей в бурятском языке и национальной языковой картине мира (зөөлэн и хатуу)

\begin{tabular}{|c|c|}
\hline & $\begin{array}{l}\text { тулалдаан 'битва, противостояние’, } \\
\text { тэмсэл 'борьба, противостояние', } \\
\text { дарлалта 'гнет', зан 'характер', Үгэ } \\
\text { 'слово’ }\end{array}$ \\
\hline 8) тупой и консервативный & $\begin{array}{l}\text { тархита 'головый', духата 'лобый', } \\
\text { хүдхэ 'непуть' }\end{array}$ \\
\hline 11) иченный & эдлэл, юумэн :'товар, вещь' \\
\hline
\end{tabular}

Перенос значения в этом случае наблюдается, как и в случае с зөөлэн, на корреляции и сходстве физической характеристики, выраженной первым значением 'твердый, жесткий; крепкий, прочный'. Например, значение 'ценный' сводимо со значением 'крепкий, прочный', т. е. представляющий ценность, или значения 'жестокий, суровый, строгий' со значением 'жесткий' : хатуу зарлиг 'указ', хатуу хүмүүжэлгэ 'воспитание', хатуу сэдьхэл 'душа', саг 'время', $x a-$ туу хабар 'весна', хатуу тулалдаан 'битва, противостояние', хатуу тэмсэл 'борьба, противостояние', хатуу зан 'характер'.

Приведем несколько примеров из произведений бурятской художественной литературы:

Фашистнууд хэды сохижо, ямаршье хатуу зан үзүүлжэ байг даа... (Б. Шойдоков, Дайсанай ара талада, 1995) 'Пусть фашисты бьются и показывают свой жестокий нрав...';

...энэ Дэлэг старшинае эрхэбэшэ барижа Үгэхэ ёһотой гэһэн хатуу сэдьхэл түрэжэ шиидэбэ (Ц. Дон, Брынзын санха, 1935) '«...этого Дэлэг-старшину надо обязательно поймать», — твердо решил он (букв. твердую душу задумал)';

Хатуу сэдьхэл - жада, / Хара һанаан - хорон (Р. Шоймарданов, Оюун түльхюур, 2006) 'Жестокая душа - копье, / Черные мысли - яд’.

Харин, тэндэ, Вьетнамда / Хатуу тэмсэл бусална... (Д. Улзытуев, Вьетнам, 1968) 'Там, во Вьетнаме / Жестокая битва кипит...' и т. д.

Метафорические переносные значения данных прилагательных закрепились в устном народном творчестве и фразеологии. В бурятском фольклоре популярны загадки-триады с формульным вопросом типа «Дэлхэйн гурбан... юун бэ?» 'Что три... на свете?', в нашем случае будут вопросы «Дэлхэйн гурбан зөөлэн юун бэ?» и «Дэлхэйн гурбан хатуу юун бэ?». В последнем случае будет разгадка:

Түмэртэ хуурай хатуу,

Для железа напильник тверд,

Үһэндэ заряа хатуу,

Хархис ноёной зарлиг хатуу

Волосы ежа жестки,

Злобного начальника указ жесток

Прилагательные зөөлэн и хатуу участвуют в образовании фразеологизмов: зөөлэн бүхэ (букв. мягкий силач) 'сон' - зөөлэн бүхэ диилээ 'заснул, задремал' (букв. мягкий силач одолел), зөөлэн алтан (букв. мягкое золото) 'пуш- 
нина'. Последний фразеологизм скорее всего является калькой русского «мягкое золото». Хатуу участвует в таких фразологизмамх, как хатуу хара (букв. твердый черный) 'водка', хатуy хүдxэ 'твердолобый, непуть' и т. д.

Рассмотренные нами прилагательные зөөлэн и хатуу обозначают физические качества предметов в прямом опыте освоения окружающего мира человеком. Полученный опыт физического воздействия/взаимодействия в процессе развития был метафорически перенесен на нефизические, ментальные и абстрактные явления и предметы. При таком переносе сохраняются основные качества, обозначаемые данными прилагательными. Каждый такой перенос, переосмысление служат конструированию национальной языковой картины мира, выражают специфику восприятия окружающего мира и отражения внутренних ощущений этноса.

\section{Литература}

1. Апресян Ю.Д. Избранные труды. Т. І. Лексическая семантика: 2-е изд., испр. и доп. М.: Школа «Языки русской культуры», Восточная литература PAH, 1995a. VIII с., 472 с.

2. Апресян Ю.Д. Образ человека по данным языка: попытка системного описания // Вопросы языкознания. 1995б. №1. С. 37-67.

3. Бачаева С. Е. Прилагательные, выражающие тактильные ощущения в калмыцком языке (на материале калмыцкого героического эпоса «Джангар» и Национального корпуса калмыцкого языка // Монголоведение. 2019. № 3. С. 613-628. DOI: 10.22162/2500-15232019-3-613-628.

4. Бачаева С. Е. Прилагательные, обозначающие температурные характеристики предметов (на материале песен калмыцкого героического эпоса «Джангар» и «Национального корпуса калмыцкого языка») // Вестник Калмыцкого института гуманитарных исследований Российской академии наук. 2016. Т. 27, вып. 5. С. 199-206.

5. Борейко Т.С. Ситуация тактильного восприятия: способы представления в системе русского языка и в языковом сознании индивида : автореф. дис. ... канд. филолог. наук: 10.02.01. Омск, 2006. 22 с.

6. Шагдаров Л. Д., Черемисов К. М. Буряад-ород толи. Бурятско-русский словарь: в 2 т. Т. І. А-Н. Улан-Удэ: Респ. тип., 2006. 636 с.

7. Шагдаров Л. Д., Черемисов К. М. Буряад-ород толи. Бурятско-русский словарь: в 2 т. Т. ІІ. О-Я. Улан-Удэ: Респ. тип., 2008. 708 с.

8. Елисеева О. А Концептуализация тактильных ощущений, связанных с восприятием поверхности объекта: дис. ... канд. филол. наук: 10.02.19. М., 2015. 240 с.

9. Корнилов О. А. Языковые картины мира как производные национальных менталитетов. 2-е изд., испр. и доп. М.: ЧеРо, 2003, 349 с.

10. Кузьмин В. В. Семантическое обогащение прилагательных вкусовой и тактильной ЛСГ в русском языке национального периода (XVII-XX вв.) автореф. дис. ... канд. филол. наук: 10.02.01. Минск, 1992. 17 с.

11. Лаенко Л. В. Перцептивный признак как объект номинации: автореф. дис. ... д-ра филолог. наук: 10.02.19. Воронеж, 2005. 44 с.

12. Нагорная А. В. Лингвосенсорика как перспективное направление современных лингвистических исследований: аналит. обзор / РАН. ИНИОН. Центр гуманит. науч.-информ. исслед. отд. языкознания; отв. ред. Э. Б. Яковлева. М., 2017. 86 с. (Сер.: Теория и история языкознания).

13. Рахилина Е. В. Когнитивный анализ предметных имен: семантика и сочетаемость. Изд-е 2-е, испр. и доп. М.: Азбуковник, 2010. 448 с. 
Б. Д. Цыренов. Лексика восприятия мягких и твердых поверхностей в бурятском языке и национальной языковой картине мира (зөөлэн и хатуу)

14. Словарь русского языка: в 4 т. / под ред. А. П. Евгеньевой. 3-е изд. стер. М.: Русский язык, 1986. 736 с.

15. Цыренов Б. Д. Лингвокогнитивный анализ прилагательных со значением положительной температуры в бурятском языке (в сравнении с русскими эквивалентами) // Филологические науки. Вопросы теории и практики. 2019. № 10. С. 333-336.

\section{VOCABULARY OF PERCEPTION OF SOFT HARD SURFACES \\ IN THE BURYAT LANGUAGE AND THE NATIONAL LANGUAGE PICTURE OF THE WORLD (zölen and khatū)}

\section{(C) Babasan D. Tsyrenov}

Science doctor in Philology, Associate Professor, Institute for Mongolian, Buddhist and Tibetan Studies SB RAS, Leading Researcher 6, Sakhyanovoy Str., Ulan-Ude, 670047, Russia tsyrenovbabasan@mail.ru

Abstract. The article examines the vocabulary of perception of hard and soft surfaces in the Buryat language and the Buryat national linguistic picture of the world. The adjectives $z \bar{o} l e n$ and $k h a t \bar{u}$, in addition to the main, direct meaning, express new meanings based on a metaphorical transfer. These values are reflected in the structure of the dictionary entry of explanatory dictionaries. If there is no explanatory dictionary, then these values are usually displayed in a bilingual dictionary. They can describe a person's character, his verbal and non-verbal actions, feelings, emotions. Positive characteristics are associated with the adjective zölen 'soft'. This is understandable: the soft character, the soft handling are just as comfortable as the soft seat, soft textile. On the contrary, uncomfortable behavior, harsh words, character, soul are associated with hard surfaces. An exception is the characterization of such positive traits as will, determination, which are also defined by the adjective khatū 'hard, solid'.

Keywords: vocabulary of perception; soft; solid; linguistic picture of the world; characteristic; soul; word; will; adjective; Buryat language.

Статья поступила в редакциию 26.10.2020; одобрена после рецензирования 13.10.2020; принята к публикации 24.12.2020. 